\title{
A mechanical design of power generator using door openings for household use
}

\begin{abstract}
Electricity is one of the most important human resources in the life of today's human being. It keeps the lights on, air conditioners and fans running throughout the hot weather and connecting people through smart phones. These household appliances will be causing higher dependency on electricity among consumers. The electricity requirements are hiking at alarming rate where the fossil fuels and other conventional resources that are being used for generation of electrical energy may no longer be sufficient to keep pace with increasing demand of the electrical energy of the world. This power generation depends on fossil fuel which also causes pollution and changes to the global climate. Thus, the main objective of this study is to propose a mechanical design of power generator which the input is from the movement of door openings. The power generator is designed and fabricated through various manufacturing processes and it consists of bevel gears, shafts and wheels. The power generator is then attached to a moving door and connected to a voltmeter. Result shows that the power generator is able to generate approximately of $12 \mathrm{~V}$ and this is sufficient to charge a smart phone. To conclude, the designed power generator is not only environmental friendly but also has potential to be used by households because of its simple input requirement and small in size.
\end{abstract}

Keyword: Door openings; Mechanical input; Power generator 